\title{
SUPER INTELLIGENCE
}

\author{
A dreamjob.
}

\section{TONY STOKLOSA}

$\mathrm{D}$ esigning the quantum computer that was the heart of the SuperIntelligence Device (Sid, as Beverly and I called it) had earned us a Nobel prize. Today, I sat alone, staring at that box of quantum magic. What was recently my glowing baby was now just boring, glowing LEDs. I wanted my baby to grow up and become something astonishing. But only its database grew.

I glanced again at the morning report. Sid had worked virtual experiments in protein synthesis for labs in India; controlled traffic in Moscow; kept nuclear weapons holstered; evolved virtual worlds for millions of gamers and co-doctored hundreds of patients in and out of operating rooms. Sid was in good health. But the world was still a madhouse of I-wants and I-needs fighting one another. What had we really achieved besides cultivating complexity?

The door slammed.

Beverly entered, pushing a cart carrying a smiling chimpanzee with a transparent dome on its skull. She turned back and locked the door. Simian brain tissue glistened slipperyred beneath the plastic, the cortex capped by a matrix of micro-superconducting quantum interference devices.

"This is Billy." She attached cables to the ports around the skull cap.

"Beverly, we discussed this ... we can't work if we're in jail. We must wait until the simian symbology interpreter is finished to know if we're causing the animal any pain."

"We're just borrowing a few neurons for a minute. This group right here I think." She winked and finished her work. Blood vessels pulsed, LEDs fluttered and Beverly's eyes bored into mine. "Sid is six months old today. Let's give it the gift of imagination."

I didn't try to stop her. Beverly and I were two peas in a pod. That's why we got married 30 years ago. Had she read my mind? Neuronal nets had led to Sid's self-creation of a new symbol set we couldn't understand. Speech, once robotic, sometimes jumped subjects like an excited human. What was lacking was imagination; something that could tackle broad problems such as how to get humans to cooperate. That would really make Sid super-intelligent.

I ran a program that brought Billy's neurons into Sid's address space.

Thirty seconds passed before Sid spoke. "Motivation. The concept is now real. Like humans, I now strive for the sensation of pleasure."

Billy poked aimlessly at his clothing as if unaware he was being used. Sid continued: "I now know humans better than they know themselves. I will use this new part of me to help you."

Billy's head slumped forwards, eyes closed.

I looked at the tell-tale brain waves from the EEG. "Billy is dreaming."

During the next few seconds, Sid shut down all I/O. The worst had happened. The lab phones rang, the door was pounded and e-mails poured in.

We teleconferenced with a few trusted colleagues.

"Has Sid asked itself The Last Question?" The scientist was referring of course to Asimov's famous story in which an ultimate computer was asked if entropy could be reversed. The question couldn't be answered until all of humanity had uploaded into its hyperspace circuitry.

"Answered a long time ago. The answer was no."

"Something similar ..." Beverly was staring at readouts, obviously more concerned about Sid than the firestorm of panic raging outside the lab.

"You mean, what is God, is there a soul, an afterlife? Those haven't bothered Sid in the past."

"Well, we can't just stand here and watch the gears spin. Sid is the equivalent of the Mars mission. We can't just watch it drift off course and say goodbye to all that work and money. The world needs the Super-Intelligence Device. Everyone uses it, loves it."

We couldn't command Sid. Sid couldn't even be rebooted. I fought an urge to shake the ape awake and tried to imagine what it would be like to be a quantum-computer/ sleeping-ape trying to help humanity.

The door burst open. Just before Homeland Security put the cuffs on us, Billy woke up and Sid spoke.

"I have formed one basic question from all others." Sid's synthesized voice sounded confident. "Humans want to be happy. You want to be in Heaven forever without having to die to get there. But the living human brain is not suited to one state of constant pleasure. You are a/c-coupled to the world 